\title{
A FRACTIONALLY INTEGRATED MODEL WITH A MEAN SHIFT FOR THE U.S. AND THE U.K. REAL OIL PRICES
}

\author{
Luis A. Gil-Alana* \\ Humboldt Universität zu Berlin, Institut für Statistik und Ökonometrie, Berlin, Germany \\ and \\ University of Navarre, Department of Economics, Pamplona, Spain
}

\begin{abstract}
In this article we model the log of the U.S. and the U.K. real oil prices in terms of fractionally integrated processes with a mean shift. We use different versions of the tests of Robinson (1994), which have standard null and local limit distributions. The results indicate that if we model the series without a mean shift, they are both nonstationary I(1). However, allowing for a mean shift during the oil crises, they become fractionally integrated with an order of integration smaller than one and thus, showing mean reverting behaviour.
\end{abstract}

Keywords: Fractional integration; Long memory: Mean shift; Real oil prices JEL Classification: $\mathrm{C} 22$

\footnotetext{
* The author gratefully acknowledges the financial support from the European TMR Grant No. ERBFMXR-CT-980213. The usual disclaimers apply.
} 


\section{Introduction}

Modelling macroeconomic time series has been a major focus of attention in the last twenty years. It was initially assumed that the series fluctuated around a deterministic trend, via a polynomial and/or a trigonometric function of time, which were fitted by linear regression techniques. A second way came after Nelson and Plosser's (1982) influential work, who following the work and ideas of Box and Jenkins (1970), argued that many macroeconomic time series may contain a unit root.

Much controversy in macroeconomics has revolved around the question of the suitability of unit roots or I(1) models for describing raw time series, which typically imply that the mean and the variance increase without bound over time, the precision of the forecast error is unbounded and the effect of the shocks persists. On the other hand, the deterministic trend approaches assume that the series, once it has been detrended, is $\mathrm{I}(0)$, implying that the mean is described by the trend function, the variance of the forecast errors remains finite and shocks have only a transitory effect. The issue of unit roots versus deterministic trend models has also very different implications in terms of economic policy. Thus, in the context of I(1) models, any shock to the economic system will have a permanent effect, so a policy action will be required to bring the variable back to its original long-term projection. On the other hand, in the deterministic I(0) approaches, fluctuations will be transitory and therefore, there will exist less need for policy action, since the series will in any case return to its trend sometime in the future.

In the last few years, however, there has been a growing literature, modelling macroeconomic time series in terms of fractionally integrated processes. We can consider the model

$$
(1-L)^{d} y_{t}=\alpha+\beta t+u_{t}, \quad t=1,2, \ldots
$$

where $y_{t}$ is the raw time series; $u_{t}$ is an $I(0)$ process, defined in this context as a covariance stationary process with spectral density function that is positive and finite at zero frequency; and $\mathrm{d}$ is a given real number. Clearly, if $\mathrm{d}=0$ in (1), $\mathrm{y}_{\mathrm{t}}$ follows the deterministic $\mathrm{I}(0)$ approaches, 
while $\mathrm{d}=1$, (with $\alpha=\beta=0$ ), implies the unit root models advocated by Nelson and Plosser (1982). However, d need not be an integer, as considered by Adenstedt (1974) and numerous subsequent authors, and the polynomial $(1-\mathrm{L})^{\mathrm{d}}$ can be expressed in terms of its Binomial expansion

$$
(1-L)^{d}=\sum_{j=0}^{\infty}\left(\begin{array}{l}
d \\
j
\end{array}\right)(-1)^{j} L^{j}=1-d L+\frac{d(d-1)}{2} L^{2}-\ldots
$$

For the time being, let's assume that $\alpha=\beta=0$ in (1). Then, if $d>0, y_{t}$ is said to be a long memory process, because of the strong association between observations widely separated in time. If $0<\mathrm{d}<0.5, \mathrm{y}_{\mathrm{t}}$ is still stationary, but its lag-j autocovariance $\gamma_{\mathrm{j}}$ decreases very slowly, like the power law $\mathrm{j}^{2 \mathrm{~d}-1}$ as $\mathrm{j} \rightarrow \infty$ and so the $\gamma_{\mathrm{j}}$ are non-summable. As $\mathrm{d}$ increases beyond 0.5 and through 1, (the unit root case), $\mathrm{y}_{\mathrm{t}}$ can be viewed as becoming 'more nonstationary' in the sense, for example, that the variance of the partial sums increases in magnitude, and if $d<1$, the process will be mean reverting with shocks affecting the series but this returns to its original level sometime in the future. Processes like (1) with positive non-integer $d$ (and $\alpha=\beta=0$ ) are called fractionally integrated and when $u_{t}$ is $\operatorname{ARMA}(p, q), y_{t}$ is fractionally ARIMA (ARFIMA(p, d, q)) process. These models were introduced by Granger and Joyeux (1980), Granger (1980, 1981) and Hosking (1981) and were justified theoretically by Robinson (1978) and Granger (1980), the former in terms of random coefficient AR(1) models, and the latter in terms of aggregation of $\mathrm{AR}(1)$ processes with a particular structure for the coefficients.

In the following section we propose a testing procedure suggested by Robinson (1994) for testing this type of models, including small variations to incorporate potential mean shifts in the original series. This is an important issue, especially in the context of time series like those used in this article (the US and the UK real oil prices). In fact, the oil crises in the mid 70's and 80's were major economic shocks with lasting effects on other economic variables (see, eg., Carruth et. al., 1998 and Blanchard, 1999). Thus, the importance of modelling this component becomes apparent. In Section 3, Robinson's (1994) procedure is applied to both real oil prices 
series. They have been widely analysed in the literature and still there is little consensus about its stochastic behaviour. Thus, for example, for the U.S. case, Carruth et al. (1999) consider that the real oil prices follow an I(1) process and look at the cointegrating relation between this variable and unemployment and real interest rates. Burbidge and Harrison (1984), Hamilton (1988) and others authors, however, consider that the real oil prices are $\mathrm{I}(0)$ and take the effect of oil price changes merely as transitory. Similar controversy arises with the U.K. data. Thus, modelling the U.K. unemployment, Bruno and Sachs (1982), and more recently, Henry and Nixon (1998) and Henry et al. (1999) argue that the real oil prices is an I(0) stationary process with a potential mean shift due to the oil crises in the mid 70's and 80's, while other authors, (eg., Harvey and Chung, 1999) find little support of this hypothesis, and suggest that the series may contain a unit root. The conclusions obtained in this article suggest that the U.S. and the U.K. real oil prices may both be I(1), though including a mean shift during the oil crises, both series become I(d) with $\mathrm{d}<1$ and thus showing mean reversion. These results are partially consistent with the original findings of Perron $(1989,1993)$ and others in that the unit root model might be rejected in the presence of structural breaks. However, extensions to the case of long memory processes have been little developed. In a recent article, Diebold and Inoue (1999) provide both theoretical and Monte Carlo evidence that structural breaks-based models and long memory processes are easily confused. Similarly, Granger and Hyung (1999) also develop a theory relating both types of models. In this article, we provide empirical evidence that the presence of deterministic mean shifts affects to the order of integration of the series, and given the lack of empirical studies based on fractional-based tests in this context, this work seems overdue.

\section{Testing $I(d)$ processes with a mean shift}

Robinson (1994) proposes a very general testing procedure for testing unit roots and other nonstationary hypotheses in raw time series. However, unlike most commonly used unit root tests, which are embedded in autoregressive (AR) alternatives, (eg. Dickey and Fuller, 1979; 
Phillips and Perron, 1988; etc.), the tests of Robinson (1994) are nested in a fractionally integrated model

$$
(1-L)^{d+\theta} x_{t}=u_{t}, \quad t=1,2, \ldots
$$

where $d$ is a given real number; $u_{t}$ is an $I(0)$ process with parametric spectral density $f$, which is a given function of frequency $\lambda$, and of unknown parameters, specifically,

$$
f\left(\lambda ; \sigma^{2} ; \tau\right)=\frac{\sigma^{2}}{2 \pi} g(\lambda ; \tau), \quad-\pi<\lambda \leq \pi
$$

where the scalar $\sigma^{2}$ and the (qx1) vector $\tau$ are unknown but $g$ is of known form. The variable $\mathrm{x}_{\mathrm{t}}$ is the error in the regression model

$$
y_{t}=\beta^{\prime} z_{t}+x_{t}, \quad t=1,2, \ldots
$$

where $\beta$ is a $(\mathrm{kx} 1)$ vector of unknown parameters; $z_{t}$ is a $(\mathrm{kx} 1)$ vector of deterministic variables that might include, for example, an intercept and/or a linear time trend, and $\mathrm{y}_{\mathrm{t}}$ is the time series we observe for $\mathrm{t}=1,2, \ldots, \mathrm{T}$.

Under the null hypothesis, defined by

$$
H_{o}: \theta=0
$$

the residuals in (2) and (3) are

$$
\hat{u}_{t}=(1-L)^{d} y_{t}-\hat{\beta} w_{t}
$$

where $\mathrm{w}_{\mathrm{t}}=(1-\mathrm{L})^{\mathrm{d}} \mathrm{z}_{\mathrm{t}}$ and

$$
\hat{\beta}=\left(\sum_{t=1}^{T} w_{t} w_{t}\right)^{-1} \sum_{t=1}^{T} w_{t}(1-L)^{d} y_{t}
$$

Unless $\mathrm{g}$ is a completely known function (eg. $\mathrm{g} \equiv 1$ as when $\mathrm{u}_{\mathrm{t}}$ is white noise), we have to estimate the nuisance parameter $\tau$, for example by $\hat{\tau}=\arg \min _{\tau \in T^{*}} \sigma^{2}(\tau)$, where $\mathrm{T}^{*}$ is a suitable subset of $R^{q}$ and

$$
\sigma^{2}(\tau)=\frac{2 \pi}{T} \sum_{j=1}^{T-1} g\left(\lambda_{j} ; \tau\right)^{-1} I\left(\lambda_{j}\right) ; \quad I\left(\lambda_{j}\right)=\frac{1}{2 \pi T}\left|\sum_{t=1}^{T} \hat{u}_{t} e^{i \lambda_{j} t}\right|^{2} ; \quad \lambda_{j}=\frac{2 \pi j}{T}
$$


The test statistic, which is derived from the Lagrange Multiplier (LM) principle, is

$$
\hat{r}=\left(\frac{T}{\hat{A}}\right)^{1 / 2} \frac{\hat{a}}{\hat{\sigma}^{2}},
$$

where

$$
\begin{gathered}
\hat{a}=\frac{-2 \pi}{T} \sum_{j=1}^{T-1} \psi\left(\lambda_{j}\right) g\left(\lambda_{j} ; \hat{\tau}\right)^{-1} I\left(\lambda_{j}\right) \\
\hat{A}=\frac{2}{T}\left(\sum_{j=1}^{T-1} \psi\left(\lambda_{j}\right)^{2}-\sum_{j=1}^{T-1} \psi\left(\lambda_{j}\right) \hat{\varepsilon}\left(\lambda_{j}\right)^{\prime} \times\left(\sum_{j=1}^{T-1} \hat{\varepsilon}\left(\lambda_{j}\right) \hat{\varepsilon}\left(\lambda_{j}\right)^{\prime}\right)^{-1} \times \sum_{j=1}^{T-1} \hat{\varepsilon}\left(\lambda_{j}\right) \psi\left(\lambda_{j}\right)\right) \\
\psi\left(\lambda_{j}\right)=\log \left|2 \sin \frac{\lambda_{j}}{2}\right| ; \quad \hat{\varepsilon}\left(\lambda_{j}\right)=\frac{\partial}{\partial \tau} \log g\left(\lambda_{j} ; \hat{\tau}\right) .
\end{gathered}
$$

Robinson (1994) established under regularity conditions that

$$
\hat{r} \rightarrow_{d} N(0,1) \quad \text { as } T \rightarrow \infty,
$$

and thus, an approximate one-sided $100 \alpha \%$ test of (4) against

$$
H_{a}: \theta>0
$$

will be given by the rule:

$$
\text { "Reject } \mathrm{H}_{\mathrm{o}} \text { if } \hat{r}>z_{\alpha} \text { ", }
$$

where the probability that a standard normal variate exceeds $z_{\alpha}$ is $\alpha$. Conversely, a test of (4) against

$$
H_{a}: \theta<0,
$$

will be given by the rule:

$$
\text { "Reject } \mathrm{H}_{\mathrm{o}} \text { if } \hat{r}<-z_{\alpha} \text { ". }
$$

Robinson (1994) also showed that the above tests are efficient in the Pitman sense that when directed against local alternatives of form $\mathrm{H}_{\mathrm{a}}: \theta=\delta \mathrm{T}^{-1 / 2}$ for $\delta \neq 0$, the limit distribution is normal with variance 1 and mean which cannot (when $u_{t}$ is Gaussian) be exceeded in absolute value by that of any rival regular statistic. Empirical applications of this procedure to several 
macroeconomic time series can be found in Gil-Alana and Robinson (1997) and Gil-Alana (2000a), and other versions of Robinson's (1994) tests, based on quarterly and monthly data, are respectively Gil-Alana and Robinson (2000) and Gil-Alana (1999).

In the empirical applications carried out in Section 3 we will implement different versions of the above tests, imposing different sets of regressors in $\mathrm{z}_{\mathrm{t}}$. Thus, we will consider the cases of $z_{t}=0$, (i.e., including no regressors in the undifferenced regression (3)); $z_{t} \equiv 1$, (i.e., including an intercept); $z_{t}=(1, t)^{\prime}$, (including a linear time trend); $z_{t}=S_{t}$, with $S_{t}=1$ if $t_{1}<t<t_{2}, 0$ otherwise, and $t_{1}$ and $t_{2}$ given values, (i.e., including a mean shift); and finally, $z_{t}=\left(1, S_{t}\right)^{\prime}$. In all these cases, the standard null and local limit distributions of Robinson's (1994) tests hold. This is another distinguishing feature of these tests compared with most unit root tests directed against AR alternatives (eg., Schmidt and Phillips, 1992), where the limit distribution can vary with features of the regressors.

In relation with the mean shift behaviour in $y_{t}$ allowed throughout the $z_{t}$ 's in (3), we can consider the model

$$
y_{t}=\beta_{1}+\beta_{2} S_{t}+x_{t}, \quad t=1,2, \ldots
$$

jointly with (2), and if we cannot reject $\mathrm{H}_{\mathrm{o}}$ (4) for a given $\mathrm{d}$, a way of testing the relative importance of the mean-shift component can be obtained by looking at the joint test

$$
H_{o}: \theta=0 \text { and } \beta_{2}=0
$$

in (2) and (11). This possibility is not addressed by Robinson (1994) but a LM test of (12) against the alternative,

$$
H_{a}: \theta \neq 0 \text { or } \beta_{2} \neq 0
$$

is suggested in Gil-Alana and Robinson (1997). It was shown in that paper that the test statistic takes the form 


$$
\begin{gathered}
\hat{r}^{2}+\frac{\left(\sum_{t=1}^{T} \tilde{u}_{t} w_{2 t}\right)^{2}}{\left[\sum_{t=1}^{T} w_{2 t}^{2}-\left(\sum_{t=1}^{T} w_{1 t} w_{2 t}\right)^{2} / \sum_{t=1}^{T} w_{1 t}^{2}\right]} \\
w_{1 t}=(1-L)^{d} 1 ; \quad w_{2 t}=(1-L)^{d} S_{t} ; \quad \widetilde{u}_{t}=(1-L)^{d} y_{t}-\widetilde{\beta}_{1} w_{1 t} ;
\end{gathered}
$$$$
\widetilde{\beta}_{1}=\left(\sum_{t=1}^{T} w_{1 t}^{2}\right)^{-1} \sum_{t=1}^{T} w_{1 t}(1-L)^{d} y_{t} ; \quad \hat{\sigma}^{2}=\frac{1}{T} \sum_{t=1}^{T} \widetilde{u}_{t}^{2}, \quad \text { and } \quad \hat{r}^{2} \text { calculated as in (5) but using } \tilde{u}_{t}
$$

just defined. We can compare (14) with the upper tail of the $\chi_{2}^{2}$ distribution. Then, rejections of (12) for a given d, which was not rejected before with (5) when testing (4) in (2) and (11), will give us certain support in favour of the mean shift behaviour in $\mathrm{y}_{\mathrm{t}}$.

\section{Empirical applications}

In this section we analyse the univariate behaviour of the log of the real oil prices series in the U.S. and the U.K. The data are quarterly and the sample sizes are 1954q1-1998q1 for the U.S. and 1966q1-1997q1 for the U.K.

Figures 1 and 2 show respectively the original series and the correlogram of the first differences in the U.S. We see in Figure 1 that the $\log$ of the U.S. real oil prices declines slowly during the 50's and 60's. It then follows a jump during the first oil crisis (1973), followed by another one during the second oil crisis (1980). Around 1986, the series seems to return to its previous level, though a much higher degree of volatility, compared with the first two decades of the sample, is then observed. The first 50 sample autocorrelation values of the series were calculated and the results clearly indicated its nonstationary nature. Looking at the autocorrelation values of the first differences, in Figure 2, we see significant values at some lags, with some decay and/or oscillation which could be indicative of fractional integration of greater than or less than a unit root.

(Figures 1 - 4 about here) 
Similarly for the U.K., Figures 3 and 4 contain respectively the plot of the original series and the correlogram for the first differences. The mean shift behaviour in the real oil prices is even more apparent here, and significant autocorrelation values are also observed in Figure 4. All these figures give us a motivation for testing fractional integration with a mean shift in the real oil prices.

In both countries we will start by testing (4) in (2) and (3) with $d=0,0.10, \ldots,(0.10)$, $\ldots, 1.90$ and 2, and white noise and autoregressive $\mathrm{u}_{\mathrm{t}}$, first with $\mathrm{z}_{\mathrm{t}}=0 ; 1$ and $(1, \mathrm{t})$, , and then including a mean shift component in $\mathrm{z}_{\mathrm{t}}$. A test of (12) in (2) and (11) will also be performed at the end of each subsection. Our findings can be briefly summarized as follows. When modelling the series without a mean shift, the results suggest that they are integrated of order 1 , though fractionally integrated processes with d slightly smaller than 1 seem also plausible. However, allowing a mean shift during the oil crises, the unit root null hypothesis is rejected in favour of less (fractionally) integrated alternatives.

\section{3a. The U.S. case}

Table 1 (and also Tables 2, 4 and 5) reports values of the one-sided test statistic $\hat{r}$ in (5), so that significant positive values of this, see (8), are consistent with (7), whereas significant negative ones, see (10), are consistent with (9). Thus, we should expect a monotonic decrease in the value of the test statistic with $d$, because, for example, if we reject $H_{o}$ (4) against the alternative (7) with $d=0.50$, an even more significant result in this direction should be expected when testing $\mathrm{H}_{\mathrm{o}}$ (4) with $\mathrm{d}=0.40$ or $\mathrm{d}=0.30$. In Table 1 we assume that $\mathrm{u}_{\mathrm{t}}$ is white noise. Starting with the assumption that there is no mean shift, (in columns 2, 3 and 4), we suppose that the regression model (3) includes respectively no regressors, an intercept and a linear time trend. The results are very similar for the three cases, which can give us an indication that neither the intercept nor the time trend are required when modelling this series. $H_{o}(4)$ cannot be rejected when $d=0.90$ and 
1, and though the unit root null hypothesis (in fact, a random walk model) appears as a plausible alternative, lower statistics are obtained in all cases with $d=0.90$.

Columns 5 and 6 in Table 1 report respectively values of $\hat{r}$ with a mean shift and with an intercept and a mean shift. If we only include a mean shift factor, (in column 5), the results are similar to those given previously, with $\mathrm{H}_{\mathrm{o}}$ (4) being non-rejected when $\mathrm{d}=0.90$ and 1 . However, if we also include an intercept, (in column 6), the unit root null is rejected, and the non-rejection values occur now at $d=0.70,0.80$ and 0.90 . Thus, we see that the inclusion of a mean shift factor in the regression model (3) can reduce the order of integration of the series and the random walk hypothesis may result in a rejection. Finally, we also observe across this table that $\hat{r}$ always decreases monotonically with d, satisfying the desirable property previously mentioned.

Table 2 reports the same statistic as in Table 1, (i.e., $\hat{r}$ in (5)), but imposing an AR(1) structure on $\mathrm{u}_{\mathrm{t}}$. Higher order autoregressions, (including seasonal autoregressions of form: $u_{t}=\sum_{j=1}^{p} \tau_{j} u_{t-4 j}+\varepsilon_{t}, \quad \mathrm{p}=1$ and 2), were also performed, obtaining similar results to those obtained for the AR(1) case, and are not reported here. If we do not include a mean shift, we observe in this table a lack of monotonic decrease in the value of $\hat{r}$ with respect to d, and this happens for the three cases of no regressors, an intercept and an intercept and a time trend. This lack of monotonicity may indicate that the model is misspecified, since in the event of misspecification, (which, in this so specialized model is likely to occur), monotonicity is not necessarily to be expected. Computing $\hat{r}$ for different values of $\mathrm{d}$ is thus useful in revealing possible misspecification, though monotonicity is by no means necessarily strong evidence of correct specification. Looking at the results with a mean shift, if $z_{t}=S_{t}$, we still observe a lack of this property. However, including also an intercept, $\hat{r}$ is always monotonic with $\mathrm{d}$, and the nonrejection values of $\mathrm{d}$ range then between 0.40 and 0.90 . Therefore, the unit root null again produces a rejection and the lowest statistic is now obtained when $d=0.70$, implying nonstationarity but mean reversion. The results in this table (and also in the previous one) 
suggest that the mean shift factor should be taken into consideration when modelling this series, the order of integration being then smaller than 1 and thus, showing mean reverting behaviour.

(Tables 1 - 3 about here)

In view of Tables 1 and 2 there is some interest in testing jointly the order of integration and the mean shift factor. Table 3 reports the statistic (14) for the same values of $d$ as before. We see that if $u_{t}$ is white noise, $H_{o}(12)$ is not rejected when $d=0.90$ and 1 , which is consistent with the results in Table 1 when the mean shift was not included in the regression model (3). However, imposing an AR(1) structure on the disturbances, the null always results in a rejection, suggesting, in view of the non-rejection values observed in Table 2 , that the mean shift factor may be important when modelling this series.

We can summarize the results obtained in this section by saying that if $\mathrm{u}_{\mathrm{t}}$ is white noise, the I(1) hypothesis cannot be rejected, suggesting that the log of the real oil prices in the U.S. may be modelled as a random walk. However, including a mean shift during the oil crises, the unit root null is rejected and smaller orders of integration seem more plausible. Allowing autocorrelated disturbances and a mean shift component, the tests of Robinson (1994) suggest orders of integration ranging between 0.40 and 0.90 and, testing jointly the order of integration and the mean shift factor, the results emphasize the importance of the mean shift component.

\section{3b. The U.K. case}

Tables 4 and 5 are analogous to Tables 1 and 2 above, showing the results of $\hat{r}$ in (5), i.e., testing (4) in (2) and (3), with white noise and AR(1) disturbances. Starting with white noise $u_{t}$, in Table 4, we see that the results are very similar to those obtained in the U.S. Thus, if we do not include a mean shift in the regression model (3), (Columns 2, 3 and 4), $\mathrm{H}_{\mathrm{o}}$ (4) cannot be rejected when $\mathrm{d}=0.90,1$ and 1.10 , and the lowest statistic is obtained in all cases when $\mathrm{d}=1$. Including a mean shift during the oil crises, (Column 5), the non-rejection values are only 0.90 and 1 , and including also an intercept, (Column 6), the unit root null hypothesis is now rejected 
in favour of less integrated alternatives. The non-rejection values range now between 0.60 and 0.90 , the lowest statistic being achieved in this case when $d=0.70$.

Table 5 reports the results with $\operatorname{AR}(1) u_{t}$. As with the U.S. data, we see that in all except the last column, the values of $\hat{r}$ are non-monotonic with d, which may suggest that these models are misspecified. Including, however, an intercept and a mean shift factor, monotonicity is always achieved and the non-rejection values range now between 0.30 and 0.70 . We see in this column that the lowest statistic across $d$ is obtained when $d=0.30$, which may indicate that this series is stationary but with a long memory behaviour. Extending the model to allow higher autoregression orders, the results were similar: $\hat{r}$ was non-monotonic with $\mathrm{d}$ in all cases except when $\mathrm{z}_{\mathrm{t}}=\left(1, \mathrm{~S}_{\mathrm{t}}\right)^{\prime}$ and $\mathrm{H}_{\mathrm{o}}(4)$ was not rejected when $\mathrm{d} \in[0,20,0.70]$. Thus, if we allow weakly autocorrelated disturbances and a mean shift during the first and the second oil crises, the unit root null hypothesis is decisively rejected and smaller orders of integration seem more adequate.

\section{(Tables $4-7$ about here)}

Table 6 corresponds to Table 3, showing the results of the statistic (14) and thus, testing (12) against (13) in (2) and (11), with $d=0,0.10, \ldots, 1,1.10, \ldots, 1.90$ and 2, and again, white noise and $\mathrm{AR}(1)$ disturbances. If $\mathrm{u}_{\mathrm{t}}$ is white noise, we observe three non-rejection cases, corresponding to values of $\mathrm{d}=0.90,1$ and 1.10 , which is completely in line with the results given in Table 4 (Column 3). However, if $u_{t}$ is $A R(1), H_{o}(12)$ is always rejected. Thus, given the non-rejected values observed in Table 5 (last column), we may conclude by saying that if we model this series with AR(1) disturbances, the mean shift factor should be taken into account, the integration order being smaller than 1 and thus, showing mean reverting behaviour.

\section{Concluding comments}

We have analysed in this article the univariate behaviour of the U.S. and the U.K. real oil prices in terms of fractionally integrated processes. We use the tests of Robinson (1994) for testing unit roots and other fractionally integrated hypotheses, which have standard null and local asymptotic 
distributions. A small variation in his tests permit us to consider fractional models with a mean shift factor, this not affecting to the limit distribution of the test statistics.

Testing the order of integration of both individual series without considering the mean shift factor, the results indicate that both series may contain a unit root, though smaller orders of integration also appear plausible. However, including a mean shift, due to the oil crises during the mid 70's and 80's, the unit root null hypothesis always results rejected and smaller order of integration seem to be more adequate. Testing jointly the order of integration and the mean shift factor, the results emphasize the importance of the mean shift component, especially if the disturbances are weakly autocorrelated. The results based on autoregressive disturbances were similar for the different AR orders whether or not the mean shift was considered. It would be worthwhile proceeding to get some optimal way of choosing the appropriate order of autoregression. However, the main goal of the paper was to show if the order of integration of the series changed with the inclusion of a mean shift and, in that respect, the short-run dynamics were not much informative. In addition, Robinson's (1994) tests generate simply computed diagnostics for departures from any real $\mathrm{d}$ and thus, it is not at all surprising that, when fractional hypotheses are confounded with autoregressions, evidence supporting different models appears. A nice feature observed in this context is that the order of integration does not much change with the AR orders, thus, finding support for a given null hypothesis across the different short-run dynamics.

The significance of the mean shift component when modelling individually the real oil prices series is crucial for the practitioner. Thus, if we do not take into account this effect, the series may appear to be $\mathrm{I}(1)$, being in fact $\mathrm{I}(\mathrm{d})$ with $\mathrm{d}<1$. Furthermore, when testing (4) in (2) and (11), the estimated $\beta_{2}$ results significant in both series, in practically all cases where $H_{o}(4)$ cannot be rejected, thus giving further evidence for the inclusion of the mean shift component in the regression model (3). 
Finally, finite sample critical values of the tests of Robinson (1994) can be computed in this context of mean shift behaviour. However, as it was shown by Gil-Alana (2000b), (for the case of no regressors and of a linear time trend), the difference in the power of Robinson's (1994) tests when using the asymptotic and the finite-sample critical values is small for samples of size similar to those used in this application. Thus, the results should not differ much in this context of deterministic shifts.

\section{Acknowledgements}

The author gratefully acknowledges the valuable comments of an anonymous referee. He also thanks for financial support from the European TMR Grant No. ERBFMXR-CT-98-0213. 


\section{References}

Adenstedt, R.K., 1974. On large sample estimation for the mean of a stationary random sequence. Annals of Statistics 2, 1095-1107.

Box, G.E.P., Jenkins, G.M., 1970. Time series analysis, forecasting and control. San Francisco, Holden Day.

Blanchard, O., 1999, Revisiting European unemployment: Unemployment, capital accumulation and factor prices, NBER Working paper 6566.

Bruno, M., Sachs, J., 1982. Input price shocks and the slowdown of economic growth. The case of U.K. manufacturing. Review of Economic Studies 49, 679-705.

Burbidge, J., Harrison, A., 1984. Testing for the effects of the oil-price rises using vector autoregressions. International Economic Review 25, 459-484.

Carruth, A., Hooker, M., Oswald, A., 1998. Unemployment equilibria and input prices: Theory and evidence for the United States. The Review of Economics and Statistics 80, 621-628.

Dickey, D.A., Fuller, W. A., 1979. Distributions of the estimators for autoregressive time series with a unit root. Journal of the American Statistical Association 74, 355-367.

Diebold, F.X., Inoue, A., 1999, Long memory and structural change, Preprint.

Gil-Alana, L.A., 1999, Testing fractional integration with monthly data, Economic Modelling 16, 613-629.

Gil-Alana, L.A., 2000a, Mean reversion in the real exchange rates, forthcoming in Economic Letters.

Gil-Alana, L.A., 2000b, Evaluation of Robinson's (1994) tests in finite samples, forthcoming in Journal of Statistical Computation and Simulation.

Gil-Alana, L.A., Robinson, P.M., 1997. Testing unit roots and other nonstationary hypotheses in macroeconomic time series. Journal of Econometrics 80, 241-268.

Gil-Alana, L.A., Robinson, P.M., 2000, Testing of seasonal fractional integration in the UK and Japanese consumption and income, forthcoming in Journal of Applied Econometrics. 
Granger, C.W.J., 1980. Long memory relationships and aggregation of dynamic models. Journal of Econometrics 14, 227-238.

Granger, C.W.J., 1981. Some properties of time series data and their use in econometric model specification. Journal of Econometrics 16, 121-130.

Granger, C.W.J., Hyung, N., 1999, Occasional structural breaks and long memory, Discussion paper 99-14, University of California, San Diego.

Granger, C.W.J., Joyeux, R., 1981. An introduction to long memory time series and fractional differencing. Journal of Time Series Analysis 1, 15-29.

Hamilton, J.D,. 1988. A neoclassical model of unemployment and the business cycle. Journal of Political Economy 96, 593-617.

Harvey, A.C., Chung, C.-H., 1999. Estimating the underlying change in U.K. unemployment. Mimeo.

Henry, S.G.B., Karanassou, M., Snower, D., 1999. Adjustment dynamics and the natural rate. An account for U.K. unemployment. Mimeo.

Henry, S.G.B., Nixon, J., 1999. Unemployment dynamics in the U.K.. Centre for Economic Forecasting, London Business School, Discussion Paper 20, (forthcoming in Oxford Economic Papers).

Hosking, J.R.M., 1981. Modelling persistence in hydrological time series using fractional differencing. Water Resources Research 20, 1898-1908.

Nelson, C.R., Plosser, C.I., 1982. Trends and random walks in macroeconomic time series. Journal of Monetary Economics 10, 139-162.

Perron, P., 1989, The great crash, the oil price shock and the unit rot hypothesis, Econometrica $57,1361-1401$.

Perron, P., 1993, Trends, unit roots and structural change in macroeconomic time series, Unpublished manuscript, University of Montreal, Montreal. 
Phillips, P.C.B., Perron, P., 1988. Testing for a unit root in a time series regression. Biometrika $75,335-346$.

Robinson, P.M., 1978. Statistical inference for a random coefficient autoregressive model. Scandinavian Journal of Statistics 5, 163-168.

Robinson, P.M., 1994. Efficient tests of nonstationary hypotheses. Journal of the American Statistical Association 89, 1420-1437.

Schmidt, P., Phillips, P.C.B., 1992. LM tests for a unit root in the presence of deterministic trends. Oxford Bulletin of Economics and Statistics 54, 257-287. 


\begin{tabular}{|c|c|c|c|c|c|}
\hline \multicolumn{6}{|c|}{ TABLE 1} \\
\hline \multicolumn{6}{|c|}{$\begin{array}{l}\text { Testing (4) in (2) and (3) with white noise disturbances in the log of the } \\
\text { U.S. real oil prices }\end{array}$} \\
\hline & \multicolumn{3}{|c|}{ No mean shift } & \multicolumn{2}{|c|}{ With a mean shift } \\
\hline $\mathrm{d}$ & $\mathrm{z}_{\mathrm{t}}=0$ & $\mathrm{z}_{\mathrm{t}} \equiv 1$ & $z_{\mathrm{t}}=(1, \mathrm{t})^{\prime}$ & $\mathrm{z}_{\mathrm{t}}=\mathrm{S}_{\mathrm{t}}$ & $\mathrm{z}_{\mathrm{t}}=\left(1, \mathrm{~S}_{\mathrm{t}}\right)^{\prime}$ \\
\hline 0.00 & 29.28 & 29.28 & 28.34 & 32.28 & 20.20 \\
\hline 0.10 & 20.20 & 27.05 & 26.52 & 30.58 & 17.13 \\
\hline 0.20 & 18.81 & 24.13 & 23.94 & 26.39 & 13.95 \\
\hline 0.30 & 17.03 & 20.51 & 20.57 & 20.46 & 10.87 \\
\hline 0.40 & 14.49 & 16.40 & 16.59 & 15.49 & 8.04 \\
\hline 0.50 & 11.42 & 12.19 & 12.39 & 11.57 & 5.55 \\
\hline 0.60 & 8.17 & 8.29 & 8.43 & 8.08 & 3.42 \\
\hline 0.70 & 5.10 & 4.99 & 5.06 & 4.96 & 1.59' \\
\hline 0.80 & 2.49 & 2.38 & 2.41 & 2.35 & 0.06 \\
\hline 0.90 & 0.43 & 0.39 & 0.41 , & $0.31^{\prime}$ & -1.19 \\
\hline 1.00 & $-1.10^{\prime}$ & -1.07 & -1.06 & -1.20 & -2.19 \\
\hline 1.10 & -2.23 & -2.15 & -2.15 & -2.31 & -2.97 \\
\hline 1.20 & -3.05 & -2.96 & -2.96 & -3.12 & -3.59 \\
\hline 1.30 & -3.67 & -3.57 & -3.58 & -3.73 & -4.07 \\
\hline 1.40 & -4.15 & -4.05 & -4.05 & -4.19 & -4.45 \\
\hline 1.50 & -4.53 & -4.42 & -4.13 & -4.57 & -4.76 \\
\hline 1.60 & -4.85 & -4.73 & -4.73 & -4.87 & -5.00 \\
\hline 1.70 & -5.11 & -4.97 & -4.97 & -5.13 & -5.20 \\
\hline 1.80 & -5.33 & -5.17 & -5.17 & -5.35 & -5.37 \\
\hline 1.90 & -5.52 & -5.34 & -5.34 & -5.54 & -5.50 \\
\hline 2.00 & -5.69 & -5.49 & -5.49 & -5.70 & -5.62 \\
\hline
\end{tabular}

$\mathrm{S}_{\mathrm{t}}=1$ for $\mathrm{t} \in(1973 \mathrm{q} 4,1980 \mathrm{q} 1), 0$ otherwise. ' $:$ Non-rejection values of the null hypothesis (4) at the $95 \%$ significance level. 


\begin{tabular}{|c|c|c|c|c|c|}
\hline \multicolumn{6}{|c|}{ TABLE 2} \\
\hline \multicolumn{6}{|c|}{$\begin{array}{c}\text { Testing (4) in (2) and (3) with AR(1) disturbances in the log of the U.S. } \\
\text { real oil prices }\end{array}$} \\
\hline & \multicolumn{3}{|c|}{ No mean shift } & \multicolumn{2}{|c|}{ With a mean shift } \\
\hline $\mathrm{d}$ & $z_{t}=0$ & $z_{t} \equiv 1$ & $z_{t}=(1, t)$ & $\mathrm{z}_{\mathrm{t}}=\mathrm{S}_{\mathrm{t}}$ & $\mathrm{z}_{\mathrm{t}}=\left(1, \mathrm{~S}_{\mathrm{t}}\right)^{\prime}$ \\
\hline 0.00 & -1.63 & -1.63 & $-1.77^{\prime}$ & -0.14 & 4.45 \\
\hline 0.10 & -4.04 & -2.31 & -2.42 & -2.40 & 4.27 \\
\hline 0.20 & -4.63 & -2.72 & -2.79 & -4.51 & 4.17 \\
\hline 0.30 & -5.44 & -2.46 & -2.41 & -6.05 & 2.71 \\
\hline 0.40 & -6.70 & -0.61 & -0.29 & -7.21 & -0.66 \\
\hline 0.50 & -8.75 & 7.82 & 2.25 & -8.94 & 0.22 \\
\hline 0.60 & -12.41 & 2.20 & 2.49 & -12.25 & 0.31 ' \\
\hline 0.70 & -18.71 & $1.50^{\prime}$ & $1.65^{\prime}$ & -18.47 & -0.09 \\
\hline 0.80 & -16.45 & $0.46^{\prime}$ & $0.53^{\prime}$ & -17.86 & -0.76 \\
\hline 0.90 & -6.76 & $-0.611^{\prime}$ & -0.58 & -7.12 & -1.53 \\
\hline 1.00 & $-1.86^{\prime}$ & -1.58 & $-1.57^{\prime}$ & -1.60 & -2.28 \\
\hline 1.10 & $-0.30^{\prime}$ & -2.41 & -2.41 & $-0.008^{\prime}$ & -2.97 \\
\hline 1.20 & $-0.34^{\prime}$ & -3.09 & -3.10 & $-0.17^{\prime}$ & -3.57 \\
\hline 1.30 & $-0.86^{\prime}$ & -3.65 & -3.66 & $-0.76^{\prime}$ & -4.09 \\
\hline 1.40 & $-1.43^{\prime}$ & -4.12 & -4.12 & -1.37 & -4.53 \\
\hline 1.50 & $-1.96^{\prime}$ & -4.50 & -4.50 & -1.92 & -4.89 \\
\hline 1.60 & -2.43 & -4.81 & -4.82 & -2.41 & -5.19 \\
\hline 1.70 & -2.84 & -5.07 & -5.08 & -2.83 & -5.43 \\
\hline 1.80 & -3.21 & -5.29 & -5.29 & -3.21 & -5.63 \\
\hline 1.90 & -3.55 & -5.47 & -5.47 & -3.54 & -5.79 \\
\hline 2.00 & -3.84 & -5.63 & -5.63 & -3.84 & -5.93 \\
\hline
\end{tabular}

$\mathrm{S}_{\mathrm{t}}=1$ for $\mathrm{t} \in(1973 \mathrm{q} 4,1980 \mathrm{q} 1), 0$ otherwise. ': Non-rejection values of the null hypothesis (4) at the $95 \%$ significance level, and in bold, the non-rejections values when monotonicity in the test statistic with respect to $\mathrm{d}$ is observed. 


\begin{tabular}{|c|c|c|}
\hline \multicolumn{3}{|c|}{ TABLE 3} \\
\hline \multicolumn{3}{|c|}{$\begin{array}{l}\text { Testing (12) against (13) in (2) and (11) in } \\
\text { the log of the U.S. real oil prices }\end{array}$} \\
\hline $\mathrm{d}$ & White noise $u_{t}$ & $\operatorname{AR}(1) u_{t}$ \\
\hline 0.00 & 871.35 & 16.62 \\
\hline 0.10 & 739.86 & 13.39 \\
\hline 0.20 & 586.99 & 12.13 \\
\hline 0.30 & 423.67 & 9.92 \\
\hline 0.40 & 270.95 & 9.15 \\
\hline 0.50 & 149.91 & 8.48 \\
\hline 0.60 & 69.71 & 7.70 \\
\hline 0.70 & 25.60 & 6.90 \\
\hline 0.80 & 6.18 & 6.73 \\
\hline 0.90 & 0.61 ' & 7.83 \\
\hline 1.00 & 1.56 & 7.93 \\
\hline 1.10 & 6.05 & 8.22 \\
\hline 1.20 & 9.19 & 9.99 \\
\hline 1.30 & 13.21 & 13.29 \\
\hline 1.40 & 16.85 & 17.39 \\
\hline 1.50 & 20.04 & 20.69 \\
\hline 1.60 & 22.82 & 23.65 \\
\hline 1.70 & 25.23 & 26.27 \\
\hline 1.80 & 27.32 & 28.56 \\
\hline 1.90 & 29.16 & 30.56 \\
\hline 2.00 & 30.77 & 32.29 \\
\hline
\end{tabular}

" $:$ Non-rejection values of the null hypothesis (12) at the $95 \%$ significance level. 


\begin{tabular}{|c|c|c|c|c|c|}
\hline \multicolumn{6}{|c|}{ TABLE 4} \\
\hline \multicolumn{6}{|c|}{$\begin{array}{c}\text { Testing (4) in (2) and (3) with white noise disturbances in the log of the } \\
\text { U.K. real oil prices }\end{array}$} \\
\hline & \multicolumn{3}{|c|}{ No mean shift } & \multicolumn{2}{|c|}{ With a mean shift } \\
\hline $\mathrm{d}$ & $z_{t}=0$ & $z_{t} \equiv 1$ & $z_{t}=(1, t)$ & $z_{t}=S_{t}$ & $\mathrm{z}_{\mathrm{t}}=\left(1, \mathrm{~S}_{\mathrm{t}}\right)$ \\
\hline 0.00 & 26.17 & 26.17 & 26.03 & 26.46 & 22.45 \\
\hline 0.10 & 24.40 & 24.61 & 24.60 & 25.03 & 19.32 \\
\hline 0.20 & 21.81 & 22.41 & 22.49 & 22.19 & 15.29 \\
\hline 0.30 & 18.76 & 19.45 & 19.61 & 18.20 & 10.77 \\
\hline 0.40 & 15.38 & 15.82 & 16.05 & 14.20 & 6.52 \\
\hline 0.50 & 11.85 & 11.85 & 12.13 & 10.59 & 3.26 \\
\hline 0.60 & 8.42 & 8.09 & 8.35 & 7.31 & 1.20 ' \\
\hline 0.70 & 5.36 & 4.95 & 5.11 & 4.50 & -0.06 \\
\hline 0.80 & 2.83 & 2.52 & 2.59 & 2.17 & -0.96 \\
\hline 0.90 & 0.85 & 0.73 & 0.75 & 0.34 & -1.66 \\
\hline 1.00 & -0.62 & -0.56 & -0.56 & $-1.01 '$ & -2.24 \\
\hline 1.10 & -1.71 & $-1.51^{\prime}$ & $-1.51^{\prime}$ & -2.02 & -2.72 \\
\hline 1.20 & -2.51 & -2.21 & -2.21 & -2.77 & -3.13 \\
\hline 1.30 & -3.11 & -2.74 & -2.75 & -3.33 & -3.47 \\
\hline 1.40 & -3.86 & -3.17 & -3.17 & -3.76 & -3.76 \\
\hline 1.50 & -3.92 & -3.51 & -3.51 & -4.09 & -4.01 \\
\hline 1.60 & -4.21 & -3.79 & -3.79 & -4.36 & -4.22 \\
\hline 1.70 & -4.44 & -4.03 & -4.03 & -4.58 & -4.41 \\
\hline 1.80 & -4.63 & -4.24 & -4.24 & -4.76 & -4.57 \\
\hline 1.90 & -4.80 & -4.42 & -4.42 & -4.91 & -4.72 \\
\hline 2.00 & -4.94 & -4.58 & -4.58 & -5.04 & -4.85 \\
\hline
\end{tabular}

$\mathrm{S}_{\mathrm{t}}=1$ for $\mathrm{t} \in(1973 \mathrm{q} 4,1980 \mathrm{q} 1), 0$ otherwise. ' Non-rejection values of the null hypothesis (4) at the $95 \%$ significance level. 


\begin{tabular}{|c|c|c|c|c|c|}
\hline \multicolumn{6}{|c|}{ TABLE 5} \\
\hline \multicolumn{6}{|c|}{$\begin{array}{c}\text { Testing (4) in (2) and (3) with AR(1) disturbances in the log of the U.K. } \\
\text { real oil prices }\end{array}$} \\
\hline & \multicolumn{3}{|c|}{ No mean shift } & \multicolumn{2}{|c|}{ With a mean shift } \\
\hline $\mathrm{d}$ & $z_{t}=0$ & $\mathrm{z}_{\mathrm{t}} \equiv 1$ & $\mathrm{z}_{\mathrm{t}}=(1, \mathrm{t})$ & $z_{t}=S_{t}$ & $Z_{t}=\left(1, S_{t}\right)^{\prime}$ \\
\hline 0.00 & $-0.27^{\prime}$ & -0.27 & $-0.07^{\prime}$ & $0.71^{\prime}$ & 2.78 \\
\hline 0.10 & -2.23 & -1.35 & $-0.83^{\prime}$ & $-1.41^{\prime}$ & 2.70 \\
\hline 0.20 & -3.52 & -2.05 & $-1.34^{\prime}$ & -3.30 & 2.26 \\
\hline 0.30 & -4.76 & -2.29 & -1.28 & -4.98 & 0.02', \\
\hline 0.40 & -6.42 & $-1.41^{\prime}$ & $-0.12^{\prime}$ & -6.90 & -0.13 \\
\hline 0.50 & -9.09 & $1.18^{\prime}$ & 2.09 & -9.91 & -0.19 \\
\hline 0.60 & -12.86 & 1.95 & 2.33 & -14.70 & -1.05 \\
\hline 0.70 & -10.78 & 1.14 & 1.32 & -13.12 & -1.61 \\
\hline 0.80 & -5.48 & 0.09 & 0.17 & -6.24 & -2.01 \\
\hline 0.90 & -2.76 & $-0.86^{\prime}$ & $-0.83^{\prime}$ & -2.65 & -2.34 \\
\hline 1.00 & $-1.61^{\prime}$ & $-1.64^{\prime}$ & $-1.64 '$ & $-1.13^{\prime}$ & -2.64 \\
\hline 1.10 & $-1.31^{\prime}$ & -2.25 & -2.26 & $-0.76^{\prime}$ & -2.91 \\
\hline 1.20 & $-1.44^{\prime}$ & -2.72 & -2.73 & $-0.96^{\prime}$ & -3.15 \\
\hline 1.30 & $-1.74^{\prime}$ & -3.08 & -3.09 & -1.36 & -3.38 \\
\hline 1.40 & -2.09 & -3.38 & -3.38 & -1.81 & -3.58 \\
\hline 1.50 & -2.44 & -3.62 & -3.62 & -2.22 & -3.77 \\
\hline 1.60 & -2.76 & -3.82 & -3.82 & -2.60 & -3.95 \\
\hline 1.70 & -3.05 & -4.00 & -4.00 & -2.93 & -4.12 \\
\hline 1.80 & -3.31 & -4.16 & -4.16 & -3.22 & -4.27 \\
\hline 1.90 & -3.54 & -4.30 & -4.30 & -3.47 & -4.41 \\
\hline 2.00 & -3.75 & -4.43 & -4.43 & -3.70 & -4.54 \\
\hline
\end{tabular}

$\mathrm{S}_{\mathrm{t}}=1$ for $\mathrm{t} \in(1973 \mathrm{q} 4,1980 \mathrm{q} 1), 0$ otherwise. " Non-rejection values of the null hypothesis (4) at the $95 \%$ significance level, and in bold, the non-rejection values when the test statistic is mononotic with respect to $\mathrm{d}$. 


\begin{tabular}{|c|c|c|}
\hline \multicolumn{3}{|c|}{ TABLE 6} \\
\hline \multicolumn{3}{|c|}{$\begin{array}{l}\text { Testing (12) against (13) in (2) and (11) in } \\
\text { the log of the U.K real oil prices }\end{array}$} \\
\hline d & White noise $u_{t}$ & $\operatorname{AR}(1) u_{t}$ \\
\hline 0.00 & 728.12 & 432.7 \\
\hline 0.10 & 631.88 & 27.73 \\
\hline 0.20 & 518.01 & 20.03 \\
\hline 0.30 & 388.37 & 15.11 \\
\hline 0.40 & 256.68 & 9.32 \\
\hline 0.50 & 144.75 & 8.61 \\
\hline 0.60 & 68.53 & 7.79 \\
\hline 0.70 & 26.83 & 7.59 \\
\hline 0.80 & 8.28 & 6.89 \\
\hline 0.90 & 2.21' & 6.41 \\
\hline 1.00 & 1.80' & 7.26 \\
\hline 1.10 & 3.79' & 7.60 \\
\hline 1.20 & 6.40 & 8.93 \\
\hline 1.30 & 9.08 & 11.07 \\
\hline 1.40 & 11.63 & 13.01 \\
\hline 1.50 & 13.99 & 14.77 \\
\hline 1.60 & 16.16 & 16.38 \\
\hline 1.70 & 18.15 & 17.90 \\
\hline 1.80 & 19.99 & 19.32 \\
\hline 1.90 & 21.69 & 20.67 \\
\hline 2.00 & 23.28 & 21.96 \\
\hline
\end{tabular}

‘: Non-rejection values of the null hypothesis (12) at the $95 \%$ significance level. 